is to be introduced involving limitations on the liberty of the subject, the case for such limitations will have to be very strong before it is acceptable to Parliament.

These would be measures to deal with a situation that has arisen and has been discovered. On a longerterm policy the abnormal reaction to authority shown by the accident-prone should not arise. A child who has repeated accidents should be regarded as having a behaviour problem which needs treatment, and. the environment in which the accident-prone personality develops should be removed or altered.

\section{LONDON TO BIRMINGHAM TELEVISION LINK}

$\mathrm{A}^{\mathrm{T}}$

$\mathrm{T}$ a meeting of the Institution of Electrical Engineers on November 8, a paper entitled "The London-Birmingham Television-Cable System" was presented by T. Kilvington, F. J. M. Laver and H. Stanesby, members of the Post Office Engineering Department. This paper described the cable system which provides channels for relaying television signals simultaneously in both directions between the television broadcasting stations at Alexandra Palace and Sutton Coldfield. The corresponding radio link between these two stations was described in a paper read before the Institution last session under the title "The London-Birmingham Television RadioRelay Link", by R. J. Clayton, D. C. Espley, G. W. S. Griffith and J. M. C. Pinkham, of the Research Laboratories of the General Electric Co., Ltd., and since published in the Proceedings (98, Part 1).

The radio link provides a connexion between the Museum Telephone Exchange in London and Tele. phone House in Birmingham, with four intermediate repeater stations. Among the conditions of the overall electrical performance, specified by the Post Office, was the requirement that all terminal and repeater stations should work unattended. This feature necessitated the provision of an elaborate supervisory and monitoring system, and the installation of a complete range of standby equipment in all the signal and power circuits of the stations. The frequencies used for transmission in one direction between London and Birmingham alternate at the successive repeater stations between 917 and 937 Mc./s., and the corresponding frequencies used in the other direction are 870 and $890 \mathrm{Mc} / \mathrm{s}$. The aerial system for either transmitter or receiver consists of a dipole with a passive reflector mounted in the aperture of a paraboloidal mirror, $14 \mathrm{ft}$. in diameter. The gain of such a system is $27.5 \mathrm{db}$. over a halfwave dipole, and it is shown in the paper that a transmitter power of $6 \mathrm{~W}$. provides a satisfactory signal/noise ratio over the longest links, two of which are slightly less than forty miles. The terminal equip. ments and their associated circuits were designed to pass television signals over a band $3 \mathrm{Mc}$./s. wide, with very uniform characteristics of attenuation and phase over this frequency range, while the build-up time of the signal and the overshoot beyond the steady-state response were both required to be very small.

For some time after the opening of the Sutton Coldfield Station in December 1949, this radio link was used for programme transmission between London and Birmingham, and valuable experience was gained on its reliability and operational charac- teristics. The faults that occurred in a total operating time of four thousand hours arose mainly from electricity-supply failures, from the complexity of the control and monitoring systems, and from the accidental operation of certain keys. From the lessons which are being learned from the installation under service conditions, it seems likely that some simplification of control and monitoring facilities could be introduced into future link-systems for television and telephony.

Reverting to the more recent paper describing the complementary system of connecting by cable the London and Birmingham television stations, the authors explain that the design of the system was largely influenced by the report of the Hankey Committee published in 1945, wilich looked forward to the time when provision might be necessary for the transmission of very-high-definition colour pictures. Accordingly, it was decided to design the system so that, although initially the limit of the vision. frequency band to be transmitted would be $3 \mathrm{Mc} . / \mathrm{s}$., the system could be adapted to a much greater band width without difficulty. The cable route is about 140 miles in length, including the connexions between Alexandra Palace and Sutton Coldfield to the appropriate Post Office exchanges in London and Birmingham, respectively. Provision has been made for repeater stations at approximately three-mile intervals along the route, although at present, with the limited band-width requirement already explained, it has sufficed to equip and use only one in four of these, at a maximum spacing of less than twelve miles.

The vision-frequency signals modulate a carrier of $6.12 \mathrm{Mc} . \mathrm{s}$. at the sending-end, the lower side-band, the carrier and part of the upper side-band being transmitted over the cable. The transmission paths are provided by a pair of coaxial cables approximately one inch in diameter, and, with the repeaters at approximately twelve-mile intervals, the gain and phase delay are substantially constant from 3 to $7 \mathrm{Mc}$./s. In the event of repeater failure, change-over from working to standby equipment is effected automatically, and power for some of the intermediate repeater stations is supplied over the coaxial cables themselves. The main cable contains four other coaxial cables for telephone channels, and a number of others of the balanced-pair type, several of which are used for supervisory functions. The overall vision-frequency characteristics of the Alexandra Palace to Sutton Coldfield connexion show a total variation in gain of $0.8 \mathrm{db}$, and in phase delay of $0.04 \mu \mathrm{sec}$. for frequencies up to $3 \mathrm{Mc}$./s. Above this frequency the eut-off is rapid. The performance in respect of linearity, signal/noise ratio and time response is adequate, a fact which is supported by the reproduction in the paper of photographs showing a television test pattern before and after transmission from Alexandra Palace to Birmingham and back, that is, over twice the length of cable normally used in the exchange of programmes between these stations.

It is becoming clcar that, in the development of television and telephone systems, large national networks are likely to use both radio links and cables in a mixed cascade arrangement. This association of a trunk radio link with a cable installation in Great Britain will provide valuable experience towards the future planning and development of national and international networks in which both the radio and cable systems will play their appropriate parts. 